\title{
Modernizar para o capital: estratégias de valorização do capital na construção de Vitória-ES (1889-1930)
}

\section{Marcos Cândido Mendonça \\ Ufes}

revista

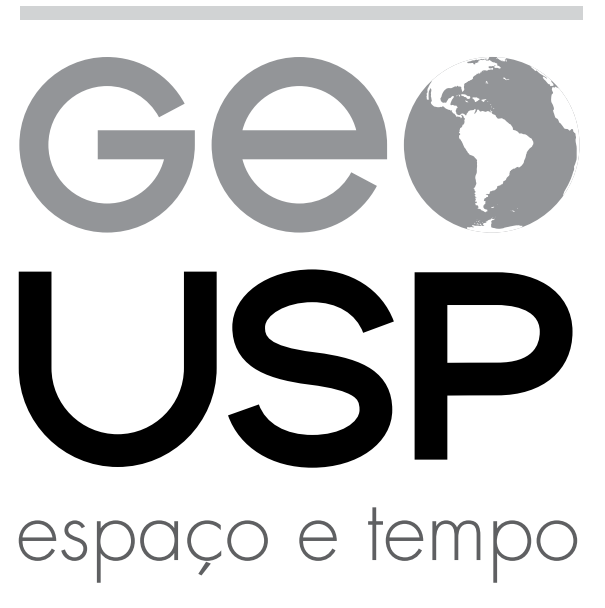

Volume $21 \cdot n^{\circ} 1(2017)$

ISSN 2179-0892
Como citar este artigo:

MENDONÇA, M. C. Modernizar para o capital: estratégias de valorização do capital na construção de Vitória-ES (18891930). Geousp - Espaço e Tempo (Online), v. 21, n. 1, p. 8-31, abril. 2017. ISSN 2179-0892.

p. 8-31

Disponível em:

$<$ http://www.revistas.usp.br/geousp/article/view/89798> . doi: 10.11606/issn.2179-0892.geousp.2017.89798.

\section{(c) $(1) \otimes$}

Este artigo está licenciado sob a Creative Commons Attribution 4.0 License. 


\section{Modernizar para o capital: estratégias de valorização do capital na construção de Vitória- ES (1889-1930)}

\section{Resumo}

Este artigo investiga a modernização de Vitória-ES na passagem do século XIX ao XX. Com essa iniciativa, promovida pelo Estado para fortalecer as funções comerciais, criaram-se na cidade novas alternativas de valorização do capital pela instalação de infraestrutura e serviços urbanos. Nesse processo, surge a perspectiva de que a valorização da propriedade imobiliária como expressão do desenvolvimento das condições gerais de produção e reprodução do trabalho possibilitou ao capital rendas futuras crescentes, como se verificou na estratégia de capitalistas locais de compra de grande número de lotes urbanos, sobretudo na área do Novo Arrabalde. Isso indica que a urbanização foi, desde os primórdios, dominada por interesses mercantil-exportadores e patrimonialistas. Esta pesquisa baseou-se em revisão bibliográfica e informações de documentos oficiais como, por exemplo, relatórios de governo e processos de alienação de terras. O referencial teórico de análise procurou apreender a cidade articulada à estrutura econômica como condições urbanas necessárias à reprodução do capital. Para isso, foi preciso compreender o significado econômico da propriedade privada da terra na construção da cidade e o papel da cidade como centro regional na estrutura produtiva estadual.

Palavras-chave: Vitória-ES. Modernização da cidade. Condições de urbanização. Infraestrutura e serviços urbanos. Propriedade imobiliária.

\section{Modernising for capital: capital appreciation strategies in the building of Vitória-ES (1889-1930)}

\section{Abstract}

This article investigates the modernization of Vitória-ES in the transition 
nineteenth century to the twentieth. By modernizing the city, promoted by the action of the State to strengthen the commercial functions of the city, were created new alternatives for capital appreciation through the construction of the city (infrastructure and urban services). In this process, there is the prospect that the appreciation of real estate development as an expression of the general conditions of production and reproduction of the work allow future rising incomes to capital; which was verified by the strategy of local capitalists to acquire large amount of urban land, mainly in the New Arrabalde area. This all indicates that urbanization was, from the beginning, dominated by commodity-exporters and patrimonial interests. This research is based on literature review and information from official documents such as government reports and land alienation processes. The theoretical analysis aimed at understanding the city articulate the economic structure, while urban conditions necessary for the reproduction of capital. For this, we need to understand the economic significance of private ownership of land for the construction of the city and the city's role as a regional center in the state productive structure.

Keywords: Vitória-ES. City modernization. Conditions of urbanization. Urban infrastructure and services. Real estate.

\section{Introdução}

Este artigo volta-se para a investigação da modernização de Vitória-ES na passagem do século XIX ao XX. Refere-se ao processo compreendido no conjunto das estratégias de investimentos de capitalistas locais na construção da cidade. Todos esses investimentos expressaram a transferência de excedentes gerados em outras atividades, principalmente nas da esfera do comércio, para a urbanização da cidade.

Segundo Maurício Abreu (1998), a modernização das cidades brasileiras significou um momento de desvalorização do passado, com sua concepção reduzida à ideia de atraso, e de valorização do novo, entendido como moderno. Assim, expressou sob a roupagem das ideologias progressistas que se propagaram por todo o país a partir da República, a rejeição e a superação do passado e seus vestígios, ocorridas em virtude de reformas urbanísticas radicais.

Nesse sentido, a modernização de Vitória se deu em um processo de urbanização da cidade, por meio da criação da infraestrutura responsável pelas condições da modernidade urbana da época. Essas condições foram, basicamente, o fornecimento de energia elétrica e água encanada, a coleta de esgoto e o fomento ao transporte urbano (bondes elétricos); acompanhadas do surgimento das modernas construções na cidade 
(Casa Pan-Americana, Vila Oscarina, Cine-teatro Glória, Teatro Carlos Gomes etc.), que seguiram o copismo da arquitetura tradicional europeia. Todas essas transformações permitiram o florescimento de um novo modo de experiência da cidade. Associadas a isso, as transformações da morfologia e arquitetura de Vitória, processo esse definido pela ruptura do passado colonial da cidade, transformaram e desfiguraram o ambiente urbano originado do período colonial e imperial. ${ }^{1}$

A análise se deu pelo estudo da produção do espaço urbano como modernização de uma cidade que cria as condições necessárias ao processo de acumulação, entre as quais, alternativas de valorização do capital por intermédio da construção da cidade. A partir do exame desse processo, entende-se a produção do espaço urbano em seu sentido substantivo, referente ao espaço físico, segundo uma ordem econômica que pode ser investigada por intermédio da relação entre capital, trabalho e terra.

A pesquisa baseou-se em revisão bibliográfica e informações de documentos oficiais (relatórios de governo e processos de alienação de terras). Esse conjunto de informações permitiu conhecer os tipos de investimentos realizados na modernização da cidade, como também os capitalistas empreendedores e a esfera de capital (agrícola, comercial ou industrial) da qual se originavam os investimentos, e, assim, oferecer ao processo em tela um entendimento da produção do espaço urbano pelo uso capitalista conferido à propriedade privada da terra e à diversificação das formas utilizadas pelo capital para se valorizar na construção da cidade.

O referencial teórico de análise pressupôs apreender a articulação da cidade à estrutura econômica como condição urbana necessária à reprodução do capital (Lefebvre, 1999; Harvey, 1982). Assim, foi necessário conhecer as condições de transferências de excedentes do núcleo do processo produtivo, que era essencialmente agrícola e estava dominada pela estrutura de comercialização da produção de café, para a urbanização da cidade; o que exigiu entender a estrutura produtiva e o papel da cidade na organização da economia regional.

$\mathrm{Na}$ economia estadual do início do século XX, por razões que discutiremos mais adiante, embora dominasse o setor do comércio de café, o poder de acumulação concentrado na esfera da circulação não se mostrou capaz de promover investimentos que pudessem estimular o quadro, até então modesto, de urbanização da Capital. Assim, Vitória, no final do século XIX, era uma cidade com uma população estimada em apenas 10 mil habitantes, e quase totalmente desprovida de qualquer infraestrutura urbana

1 Uma das evidências desse processo foi a total desfiguração da arquitetura colonial jesuítica do Palácio Anchieta (atual sede do governo), que outrora abrigou a Igreja de São Tiago e o Colégio Jesuíta; outra evidência foi a destruição da Igreja da Misericórdia, a mais antiga de Vitória, para a construção do Palácio Domingos Martins (Mendonça, 2014). 
básica, como distribuição de água e rede de captação de esgoto, e tendo um precário sistema de iluminação pública.

O fornecimento de água era realizado por chafarizes distribuídos pela cidade. Inexistindo rede de esgoto, os dejetos eram lançados, pelos próprios moradores, em horários determinados, nas valas do Campinho, na chamada rua da Vala (atual avenida República) e na maré. Citando-se um fato sintomático dessa situação, na rua do Reguinho (atual Graciano Neves) descia uma vala formada pelas águas do morro da Fonte Grande, que, ao se encontrarem com as do largo da Conceição (também chamado de Prainha, e hoje, depois de aterrado, forma a praça Costa Pereira), acumulavam-se formando uma área pantanosa (Derenzi, 1965; Elton 1986).

O primeiro sistema de iluminação pública da cidade foi instalado em 1847 , abastecido a azeite de peixe e mamona. Em 1879, se implantou o sistema de iluminação a gás na cidade, que substituiu a iluminação a querosene, instalada em 1865. Entretanto, em 1893, devido a interrupção do fornecimento a gás, a iluminação a querosene é novamente retomada, com a instalação de 150 lampiões belgas (Derenzi, 1965; Elton, 1986).

Todavia, esse quadro foi radicalmente transformado nas primeiras décadas do século XX. Com a criação dos serviços de abastecimento de água, rede de esgoto e transporte público e do novo sistema de iluminação pública, a cidade passou a ter adequadas condições de infraestrutura urbana; e ainda, com a construção de edifícios públicos e das modernas moradias na cidade, a tradicional arquitetura colonial jesuíta, característica marcante da fisionomia da cidade até então, foi substituída por outra que seguiu o padrão arquitetônico europeu, muitas vezes copiado pelos próprios construtores locais. Aliadas a isso, diversas intervenções na morfologia da cidade, como, por exemplo, a abertura da avenida Capixaba (extensão da avenida Jerônimo Monteiro), transformaram o antigo centro da cidade, antes caracterizado por uma organicidade de emaranhados de ruas típico das cidades de fundação portuguesa.

A inauguração da República, pela descentralização do poder, foi condição política essencial para a execução do projeto. Entre essas condições estavam a ampliação da participação dos governos estaduais na arrecadação via impostos e a possibilidade de eles contraírem empréstimos sem a aquiescência do governo central. Cada estado pôde desenvolver uma política de desenvolvimento regional melhor integrada aos interesses locais por meio de maior autonomia governamental (Faoro, 2008).

Agindo nesse desígnio, o Estado acertou diversos contratos com capitalistas locais e empresas de fora. Diversos contratos foram realizados entre o Estado e a Companhia Brasileira Torrens, sediada no Rio de Janeiro. Essa empresa, contratada pelo Estado, a partir de 1890, para construir o sistema de abastecimento de água e o de captação de esgoto e o porto de Vitória, ao obter para si a transferência de terrenos do governo, agiu no sentido de obter ganhos imobiliários. 
Segundo Carlos T. de Campos Júnior (2002, p. 52), "a Companhia Brasileira Torrens, acreditando na prosperidade do estado, em particular no progresso acenado para sua capital, aposta no crescimento dessa cidade". Agindo nesse escopo, a Companhia B. Torrens montou uma estratégia que consistia em vender lotes, material de construção e construir, com o objetivo de lucrar em diferentes frentes: "As obras públicas valorizavam os lotes, que seriam vendidos (pela Companhia) para receber edificações (construídas por ela), que demandaria materiais, que, por sua vez, seriam vendidos pelas fábricas pertencentes também à Companhia B. Torrens".

Embora a Companhia Brasileira Torrens não tenha obtido êxito nos seus planos (pois entrou em falência e os terrenos de sua propriedade, dado o descumprimento do contrato, retornaram ao domínio público), a estratégia da empresa serviu como pista inicial de nossas investigações para entender as estratégias utilizadas pelo capital para se valorizar na política de modernização de Vitória.

Embora o Estado buscasse empresários de fora para os contratos das obras de maior exigência técnica, verificou-se que a maior parte das obras de infraestrutura e serviços urbanos foi contratada com capitalistas locais. Nesse sentido, como compreender todas essas transformações em criação de infraestrutura e serviços urbanos pela lógica do processo de acumulação do capital? Mais precisamente, como a modernização da cidade preservou interesses da classe dominante local e qual foi o significado econômico desse processo na perspectiva do uso capitalista dado à propriedade da terra?

Todos os investimentos investigados sugerem que a política de modernização de Vitória criou novas alternativas de valorização do capital na urbanização da cidade, pelo qual a classe dominante local, pela influência no aparelho de governo, encontrou possibilidades de diversificação dos investimentos. Inclui-se nessas formas de investimento a prestação de serviços urbanos, como o fornecimento de energia, água e transporte urbano, embarque e desembarque de cargas em navios e, como consequência, o desenvolvimento do interesse na propriedade urbana, na perspectiva de a valorização imobiliária proporcionar rendas futuras com o crescimento da cidade.

Assim sendo, a perspectiva de análise buscou apreender a cidade como lócus de reprodução do capital e de reprodução da sociedade nesse processo. Dessa forma, a compreensão dos investimentos urbanos seguiu o entendimento deles como novas formas de valorização do capital por intermédio da construção da cidade. Nesse processo, surge a perspectiva de a valorização da propriedade imobiliária como expressão do desenvolvimento das condições gerais da produção e da reprodução do trabalho possibilitar rendas futuras crescentes ao capital. Daí a exigência, para efeito de análise, de entendimento do significado econômico da propriedade privada da terra para a construção da cidade (Lefebvre, 1999; Harvey, 1982). 


\section{O significado econômico da propriedade da terra para a construção da}

\section{cidade}

Busca-se nesta perspectiva uma compreensão da cidade como lócus do processo de acumulação que elucide a importância do significado econômico da propriedade da terra na produção do espaço. Intenção que exige recuperarmos aspectos do processo histórico de criação da moderna propriedade privada da terra no Brasil e sua relação com o processo de urbanização. Para tal efeito, levanta-se a seguinte questão de caráter teórico-metodológico para encaminhamento da discussão: qual o significado da extinção do trabalho escravo no contexto da produção agrário-mercantil para a metamorfose da riqueza que inaugura nova situação, em que ter riqueza já não é ser proprietário de escravos, mas de terra?

Durante a escravidão, o principal elemento de riqueza do fazendeiro era a posse do escravo como sua propriedade. A terra, mercadoria farta, detinha pouco valor e não servia como elemento para o financiamento da produção, função desempenhada pela propriedade do escravo. Na transição do trabalho escravo para o livre, ${ }^{2}$ a transformação das relações de produção foi conduzida como meio de preservar a economia mercantilexportadora, elegendo a propriedade da terra como novo elemento de garantia de empréstimos no financiamento da produção e recurso utilizado para subjugar a força de trabalho ao capital. Esse processo significou a destruição da forma arcaica de riqueza expressa na propriedade do escravo para a constituição de uma nova riqueza: a moderna propriedade de terra (Martins, 1996).

Em síntese, o sentido operacional da potencialização da terra como instrumento de hipoteca era obter a valorização mercantil da terra por meio da produção de sua escassez. Isto se fez com o empenho do Estado em assumir o custeio do transporte do imigrante em prol dos interesses dos fazendeiros (notadamente do Oeste Paulista), que buscavam uma saída para o fim do trabalho escravo; o que permitiu ao fazendeiro investir na formação de novas fazendas e aos bancos obterem um novo elemento de valor para continuarem vinculando seu capital à produção cafeeira. Para esse efeito, exigiu-se impedir que o imigrante (ao menos sua maior parte) tivesse acesso à terra por meio do título de propriedade; medida que visava facilitar a cobertura de demanda por trabalho nas fazendas (Martins, 1996).

Assim, a moderna propriedade da terra - resultado da metamorfose da riqueza,

2 A Lei de Terras, de 1850 (regulamentada em 1854), foi o instrumento legal e jurídico para, na transição para o trabalho livre, preservarem-se os interesses do capital na produção cafeeira. Lembrando que o regime de sesmaria foi abolido em 1822, a Lei de Terras definia que o acesso à terra só poderia se dar pela compra, o que impedia seu acesso por parte de grande parcela da população brasileira e imigrantes (Martins, 1996). 
portanto, da transferência da riqueza antiga baseada no escravo para a propriedade fundiária - constituiu-se em expressão mercantil de riqueza, tornando-se alvo de estratégias diversas adotadas pelo capital para, por meio de seu domínio, valorizar-se. Nesse sentido, criaram-se alternativas de valorização do capital na construção da cidade que se traduzem na perspectiva de apropriação de renda, possível pela valorização da propriedade imobiliária. Essas novas alternativas de realização do capital expressaram a inclusão do espaço inteiro no mundo da mercadoria (Harvey, 1982; Pereira, 1988, 2004).

Dado que o caráter inerente de toda produção é exigir um espaço físico, e para o ramo da construção isso é invariável, o instituto da propriedade da terra permitiu ao proprietário extrair renda pelo direito de uso e acesso a esse bem. Pela importância da propriedade da terra nessa relação, isto é, na divisão do valor socialmente produzido, a propriedade privada da terra adquiriu a qualidade de investimento independente de qualquer exploração produtiva ${ }^{3}$ (Lefebvre, 1999; Pereira, 1988, 2004).

Com isso, e associado à materialização na cidade das condições de realização da produção, houve incremento na valorização da propriedade imobiliária, elevando o potencial da terra urbana de proporcionar renda. A propriedade da terra, como condição básica para realização da produção tem seu valor determinado, no caso da construção,

[...] pela geração de rendas que pode proporcionar o seu melhor uso na produção social. Por isso, o preço da terra vai sendo determinado pela renda da terra à medida que se desenvolvem condições capitalistas de produção. A renda da terra capitalizada resulta da relação social entre proprietários de terra e do capital na partilha da mais-valia. É, portanto, o resultado de um processo social e não resultado "natural" da produção (Pereira, 1988, p. 64).

Compreendido esse aspecto do processo em tela, antes de discutirmos as estratégias empregadas pelo capital para se valorizar na modernização da cidade, apresentam-se as condições gerais da urbanização de Vitória. Sendo assim, a seguir analisou-se o espaço produtivo em que a cidade está inserida na função polarizadora de uma região, entendendo que a compreensão do papel da cidade no espaço produtivo permite compreender a transformação do seu espaço construído, analisado a partir da transferência de excedentes gerados na produção para a urbanização da cidade.

3 Isso se refere à capacidade da propriedade de terra de facultar ao proprietário participar da partilha do valor produzido sem participar efetivamente da produção. "A propriedade fundiária nada tem que ver com o processo real de produção. Seu papel se restringe a desviar do bolso do capitalista [e da sociedade como um todo] para o seu parte da mais-valia produzida" (Marx, 1985, p. 943). 


\section{Aspectos históricos da formação regional e seus reflexos na cidade de}

\section{Vitória}

A cidade de Vitória manteve-se, praticamente, isolada do restante do território do Espírito Santo até o fim do século XIX. A circulação de pessoas e mercadorias entre a capital e outras vilas e cidades que pontilhavam a costa da província era realizada por navegação costeira. Mesmo Vitória tendo alcançado certo grau de importância comercial durante o início dos anos oitocentos, em virtude da exportação da produção de alguns engenhos localizados nos arredores da cidade, sua passagem pela economia açucareira não the rendeu um espaço construído que indicasse na fisionomia o desenvolvimento característico de um espaço produtivo que lhe fosse tributário e integrado com a economia internacional ${ }^{4}$ (Araújo Filho, 1974).

Segundo Francisco de Oliveira (1982), a formação urbana, dentro das condições da economia agroexportadora fundada na monocultura, era caracterizada historicamente por uma extrema polarização: uma vasta região produtiva com sua dinâmica movida pelo complexo latifúndio-minifúndio exportador e comandada pelo centro urbano desempenhando o papel de conexão da produção colonial à economia internacional. Isso evidencia o papel da cidade na estrutura produtiva regional como elemento explicativo do caso brasileiro, pelo menos até a década de 1930.

A produção, ao ter uma base física (poderíamos dizer, espacial), é o elemento determinante na organização do espaço. A esse respeito, de acordo com David Harvey (1982, p. 6) "[...] a sociedade capitalista precisa, por necessidade, criar uma paisagem física - uma massa de recursos físicos construídos, às finalidades da produção e do consumo". A organização da estrutura produtiva exige a criação, no espaço, das condições materiais necessárias à produção (armazéns, estradas, portos etc.). Na organização da produção, alguns espaços (povoações, cidades e portos) são privilegiados, por suas condições naturais ou criadas, para a realização do processo produtivo, ou seja, a organização do espaço (e nele o papel desempenhado pela cidade) está relacionada a uma dada estrutura produtiva.

Sendo assim, para compreender a construção da cidade, é preciso entender sua participação na estrutura produtiva, que condiciona a urbanização dos investimentos; por isso, a urbanização naturalmente depende da função da cidade no contexto do

4 Embora desde o período imperial a classe dominante local já atuasse para desenvolver o setor de comércio na cidade, a participação subordinada de Vitória no complexo econômico colonial fica explícita no pedido do jovem Muniz Freire ao imperador, em 1885, requerendo incluir a cidade nas rotas regulares das navegações para o exterior. $\bigcirc$ interesse era viabilizar o crescimento econômico da província, dependendo, por isso, da subvenção temporária de companhias estrangeiras de vapores transatlânticos para estabelecer comércio direto com as praças europeias ou estadunidenses (Mendonça, 2104). 
desenvolvimento regional. Assim, analisamos as condições de urbanização de Vitória a partir do espaço tributário da cidade e das transformações socioeconômicas verificadas na transição do trabalho escravo para o livre no contexto regional. "O marco de referência foi a produção da cidade, como materialização das condições gerais, pois ela é o local privilegiado do desenvolvimento da produção e do consumo, onde se acirra a disputa pela privatização do espaço" (Pereira, 1988, p. 3).

No fim do século XIX, o café era a cultura predominante no Espírito Santo, constituindo o único gênero agrícola de destaque na pauta das exportações. Nessa época persistia uma verdadeira fragmentação espacial da produção (Mapa 1). Polarizada pela cidade de São Mateus, a região norte era dedicada principalmente à produção de farinha de mandioca e tinha menos importância econômica entre as três regiões.

A produção da região sul do Espírito Santo, principal região produtiva de tradição escravista, era escoada pelos portos do Rio de Janeiro, não favorecendo assim o comércio da capital e pouco contribuindo com a arrecadação do estado. ${ }^{5}$ Além disso, as dificuldades de reprodução do capital aplicado na grande lavoura, com a crise do trabalho (resultado do fim da escravidão), contribuíram para inibir a concentração do excedente na esfera da produção (Campos Júnior, 1996; Saletto, 1996).

Na região central, outra região de produção cafeeira, onde a produção era realizada especialmente a partir da pequena propriedade com uso do trabalho familiar imigrante, a produção ficou nos justos limites técnicos e financeiros do trabalho imigrante. A produção dessa região tinha como destino a cidade de Vitória e se realizava por um segmentado sistema de comércio que se estruturava desde o vendeiro local até algumas poucas casas de comércio em Vitória. $O$ excedente concentrado em Vitória, apropriado por uma espoliativa estrutura de comercialização, não foi suficiente no seu montante nem encontrou condições adequadas para viabilizar inversões em atividades tipicamente urbanas (Campos Júnior, 1996; Saletto, 1996).

Admite-se que, por meio das casas comerciais, o excedente era drenado, principalmente, para outros centros comerciais de maior expressão - geralmente sedes das firmas comerciais -, onde era investido, e que o excedente acumulado na estrutura produtiva do café no Espírito Santo não fluiu para outras atividades dinâmicas, no caso, a industrial. Ficou retido pelo capital mercantil-exportador, que drenava para fora do estado a maior parte desse excedente. Situação essa que não dinamizou a urbanização da capital até o final do século XIX.

5 Em 1895, iniciou-se a ligação de Vitória com a região sul, com a construção da Estrada de Ferro Sul do Espírito Santo. Contudo, só após sua alienação à Leopoldina Railway, em 1906, a estrada ligou-se a Cachoeiro de Itapemirim (no ano de 1910), cidade que já estava ligada por linha férrea a então capital do país (Rio de Janeiro), desde 1903 (Bittencourt, 1987; Quintão, 2008). 


\section{Mapa 1}

Ocupação territorial do Espírito Santo na última década do século XIX: cidades-polo importantes no escoamento da produção e respectivas regiões produtivas - região central: Vitória; região norte: São Mateus; região sul: Cachoeiro de Itapemirim

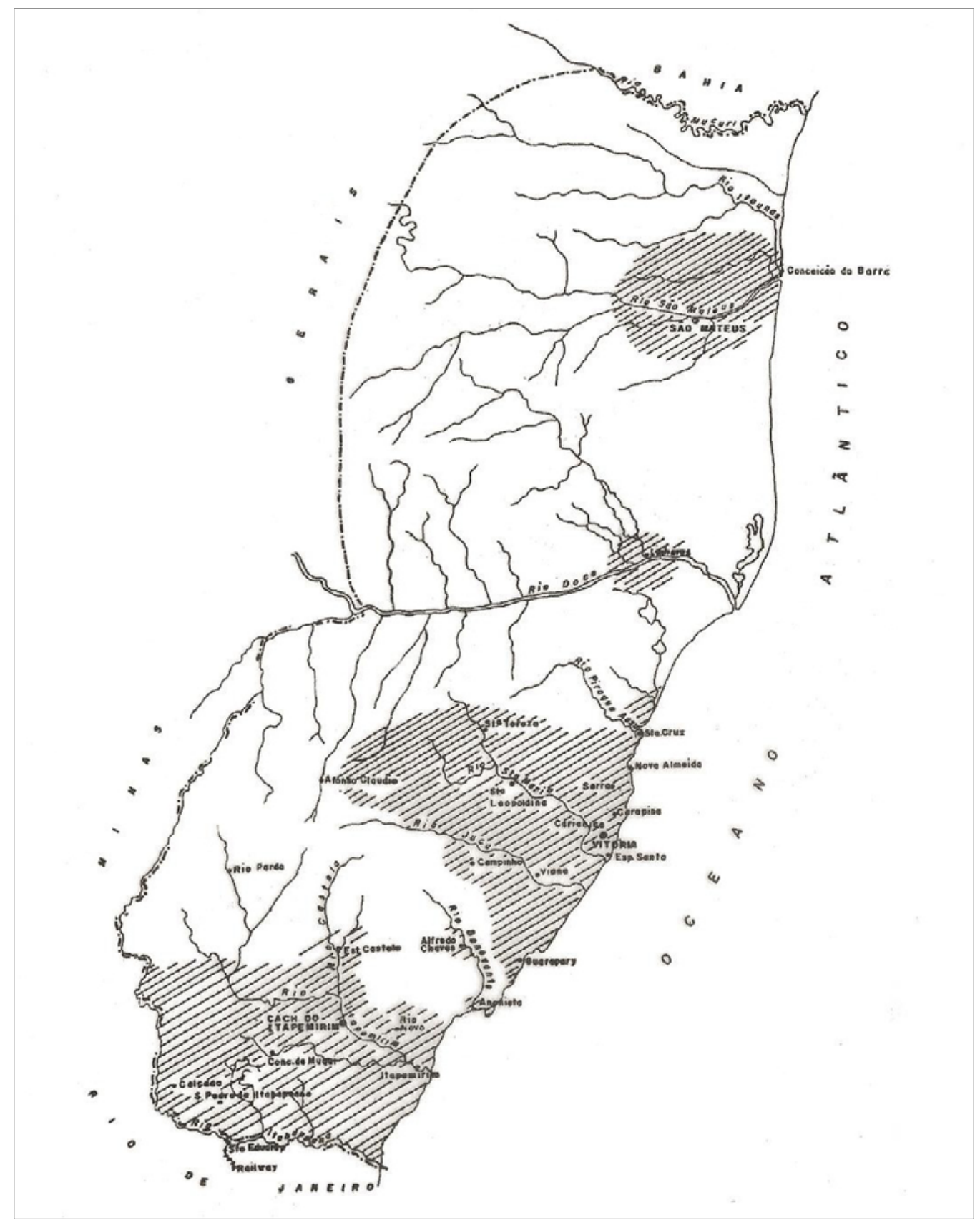

fonte: Campos Júnior (1996).

Sendo assim, pelo fato de o excedente de trabalho acumulado na esfera do comércio ser drenado para outras regiões e não ter se mostrado suficiente para transformar as bases locais da economia, essa conjuntura econômica funcionou como um limite à transformação do espaço físico da cidade por meio de investimentos via setor privado. Por isso, como esclareceu Campos Júnior: 
O governo aparece como agente supremo desse processo à frente de qualquer investida do setor privado. $\mathrm{Na}$ ausência, na região central, de capitalistas locais de expressão que movessem iniciativas, o governo surge como o grande concentrador e centralizador do excedente produtivo, atuando, não somente como um ator subsidiário de ações regulatórias de participação marginal de poder, mas participando efetivamente como promotor do novo ambiente a ser construído (Campos Júnior, 1996, p. 198-199).

A atuação do Estado tinha como principal desígnio produzir um novo espaço urbano compatível com os interesses dominantes no aparelho de poder estadual. Visava, assim, atender os interesses do capital mercantil-exportador, transformando Vitória em um centro de comércio de expressão nacional, o que foi possível pela criação de infraestrutura de transporte ferroviário (ligando Vitória à região sul do Espírito Santo e com o estado vizinho de Minas Gerais), pela construção do porto de Vitória, ${ }^{7}$ pela expansão da cidade por meio do Novo Arrabalde e do aterro do arrabalde do Campinho ${ }^{8}$ e pelas obras de infraestrutura e serviços urbanos que transformaram o ambiente construído da cidade. Todas essas transformações permitiram à cidade desenvolver suas funções comerciais.

O Mapa 2 nos dá uma ideia do espaço ocupado pela cidade de Vitória no final do século XIX e da dimensão do plano do Novo Arrabalde, concebido no governo Muniz Freire (1892-1896) e elaborado por Saturnino de Brito. O Mapa 2 traz um esboço da ilha de Vitória, com a cidade (centro antigo) edificada entre o maciço central da ilha e o canal ao sul da ilha. Adjacente à cidade, também observamos o arrabalde do Campinho, área conquistada ao mar e urbanizada no governo Jerônimo Monteiro (1908-1912). Na região de praias, a leste da ilha, localiza-se a área escolhida para o Novo Arrabalde, que, abrangendo originalmente uma área de $2.738 .098 \mathrm{~m}^{2}$ (descontados os morros e a Vila Monjardim, que não foi construída), assim que concluído anexaria uma área cinco vezes maior ao espaço ocupado da cidade (Brito, 1896).

6 O sistema ferroviário planejado compreendia a Estrada de Ferro Sul do Espírito Santo, que passou a ligar Vitória a Cachoeiro de Itapemirim, localizada na região sul, e ficou concluída em 1910, e a Estrada de Ferro Vitória a Minas, iniciada em 1903, ficando concluída em 1915, que, por sua vez, ligou Vitória e a capital mineira. Do ponto de vista técnico, a construção dessas duas estradas permitiu maior convergência da produção de café para Vitória (Bittencourt, 1987).

7 porto de Vitoria localiza-se no canal sul da ilha. Antes de sua construção, quando não havia nenhuma infraestrutura portuária, como cais para atracamento, os navios operavam no largo do canal da ilha. Suas obras de construção começaram em 1911, mas foram paralisadas em 1914. Em 1924, no governo Florentino Avidos (1924-28), foram retomadas, ficando concluída em 1929 a ponte Florentino Avidos (também chamada de Cinco Pontes), que liga Vitória a Vila Velha, e em 1937 se concluiu a primeira seção do cais, permitindo que os navios operassem diretamente no porto. Os trabalhos ficaram definitivamente concluídos em 1940 (Araújo Filho, 1974; Siqueira, 1984).

8 Projetado em 1895, pelo governo Muniz Freire (1892-96), o Novo Arrabalde, que previa a ocupação da área de praias da ilha, só começou a ser ocupado a partir dos anos 1920, quando o Estado dotou a área de infraestrutura de transporte e abastecimento de água. Mas logo foi aterrado o arrabalde do Campinho, adjacente ao centro antigo da cidade, dando origem ao novo bairro da Vila Moscoso, construído no governo de Jerônimo Monteiro (1908-12) (Campos Júnior, 1996). 


\section{Mapa 2}

Ilha de Vitória-ES: esboço de Vitória e do Novo Arrabalde - 1896

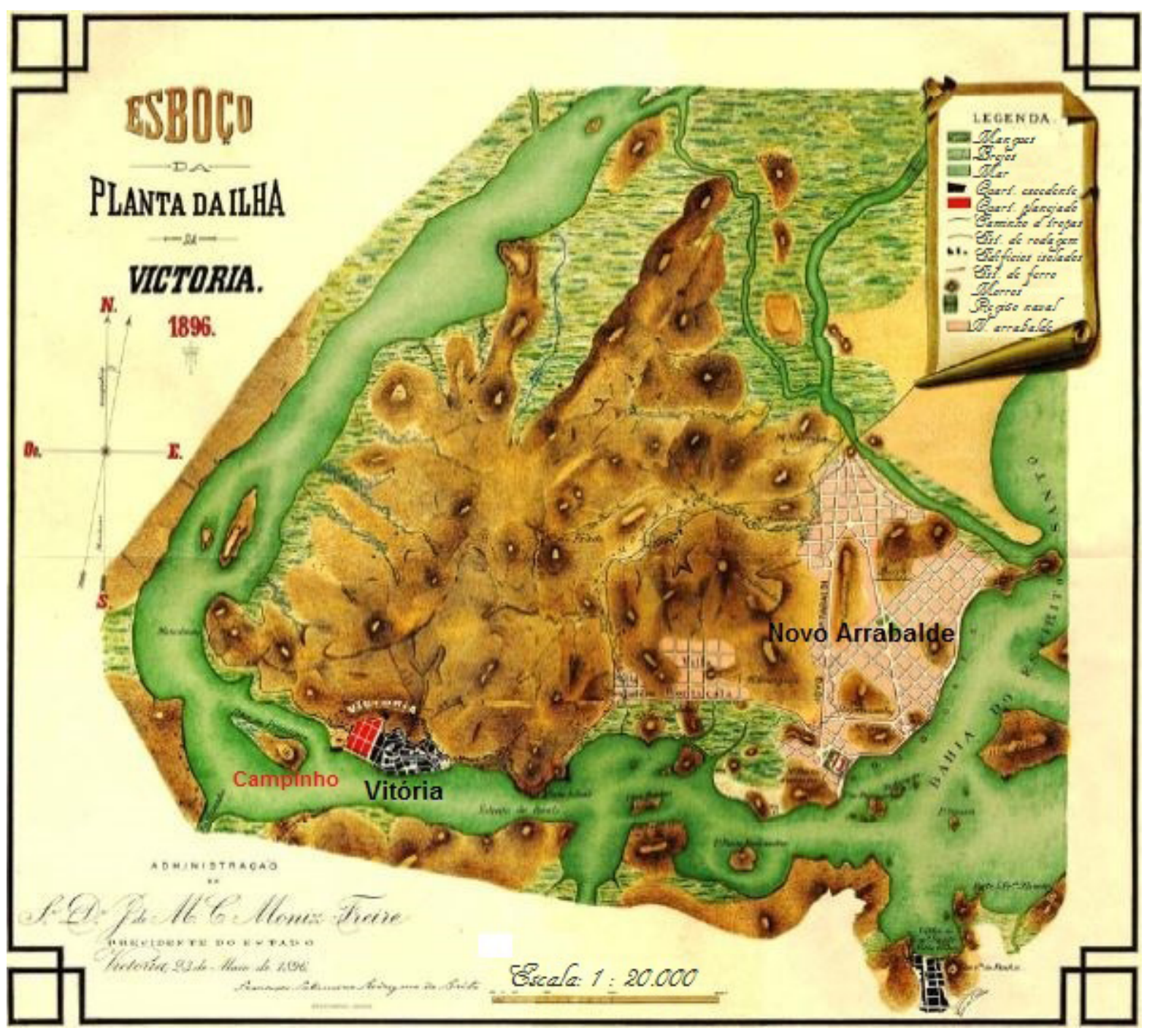

fonte: Reproduzido do "Esboço da planta da ilha de Vitória, 1896", Saturnino de Brito (Campos Júnior, 1996).

Nesse projeto, contando com a participação do Estado, que assumiu a criação e o aperfeiçoamento da infraestrutura da cidade, capitalistas locais atuaram no processo de modernização da cidade buscando novas alternativas de valorização do capital. Essas alternativas são o tema da investigação a seguir.

\section{Estratégias de investimentos na modernização de Vitória}

No tocante aos investimentos analisados, ${ }^{9}$ identificou-se que a modernização da cidade proporcionou as condições para diversificar os investimentos no interior do

9 Outros tipos de investimento em infraestrutura e serviços urbanos foram a construção de habitações, hotelaria e teatro e transporte urbano e de cargas (Mendonça, 2014). 
crescimento da cidade. Nesse processo, temos as primeiras experiências do capital na busca de sua valorização na construção da cidade, quando surgem intrinsecamente atreladas ao desempenho do Estado nessa tarefa.

\section{Serviços urbanos: água, luz e esgoto}

A criação dos serviços urbanos de abastecimento de água, rede de esgoto e fornecimento de energia elétrica proporcionou novas alternativas de investimentos no processo de modernização da cidade. Esses investimentos surgem atrelados à criação, por parte do Estado, das condições materiais necessárias ao desenvolvimento das funções comerciais da cidade.

governo Jerônimo Monteiro contratou, em 11 de novembro de 1908, com o paulista Dr. Augusto Ferreira Ramos a instalação dos serviços de água, luz e esgoto pela importância de 2.100:000\$000 (dois mil e cem contos de réis), com prazo de 14 meses para a conclusão das obras. ${ }^{11}$

Enquanto os serviços de abastecimento de água eram executados para atender provisoriamente essa necessidade, com o empresário local Antenor Guimarães foi acertado o fornecimento de água da cidade. $O$ serviço consistia na entrega de água em domicílio à razão de $\$ 050$ (cinquenta réis) o barril de 16 litros, pagos pelo consumidor, recebendo o contratante mensalmente o valor de $400 \$ 000$ (quatrocentos mil réis) pela prestação do serviço. $O$ serviço era realizado durante todo o dia e nas primeiras horas da noite com o emprego de seis veículos-pipa (Espírito Santo, 1909, contrato n. 2, p. 16).

Com o mesmo capitalista, em fevereiro de 1909, foi contratado, pelo prazo de três anos, o serviço de limpeza pública e domiciliar da Capital. Compreendia varredura diária das ruas, capinação, irrigação e remoção de lixo dos domicílios e terrenos particulares e públicos. Pelo contrato ficou estabelecida ao contratado a remuneração de 3:333\$333 (três contos e trezentos e trinta e três mil e trezentos e trinta e três réis) mensais pela execução do serviço (Espírito Santo, 1909, contrato n. 2, p. 5).

A primeira ligação de água ficou instalada em agosto de 1908, com o abastecimento feito ao Palácio Anchieta (sede do governo) e repartições públicas (Espírito Santo, 1909, contrato n. 2, p. 16). A inauguração oficial do serviço de abastecimento de água e iluminação pública se realizou no dia 25 de setembro de 1909. Quanto ao abastecimento

10 Para efeito de comparação dos valores mencionados no artigo, informamos os valores de algumas mercadorias vendidas no interior da região central do Espírito Santo, mais precisamente em Porto do Cachoeira de Santa Leopoldina, entre 1895 e 1900: 1 garrafa de cerveja nacional (\$600), 1 garrafa de vinho do porto (4\$000), 1 garrafa de querosene $(\$ 600)$ e 1 quilo de carne seca (1\$100) (Wernicke, 2013).

11 contrato estabelecia as parcelas de pagamento da seguinte maneira: 600\$000 pagos até 30 dias após aprovação do contrato; 500:000\$000 pagos quando se encontrasse no porto da capital todo o material necessário para as obras; 500:000\$000 quando se concluíssem 50\% dos trabalhos; e 500:000\$000 na conclusão do serviço (Espírito Santo, 1909, contrato n. 2, p. 3). 
de água, foram instaladas 970 ligações em domicílios, gerando inicialmente uma renda mensal de 6:800\$000 (seis contos e oitocentos mil réis). $O$ fornecimento de energia em domicílio, iniciado com 229 instalações, gerou, nos primeiros meses de 1910, a renda mensal de 3:200\$000 (três contos e duzentos mil réis), considerada ainda pequena, mas com incrível capacidade de expansão, segundo o diretor de Agricultura, Terras e Obras, Dr. Antonio F. de Athayde. ${ }^{12}$

$\mathrm{Na}$ década de 1920, esses serviços foram reunidos em uma mesma gerência de controle do Estado com a criação da empresa Serviços Reunidos de Vitória, compreendendo água, esgoto, iluminação e bondes elétricos. No governo Florentino Avidos (1924-1928), o Estado retomou os serviços de água e esgoto. Para isso, o governo reconstruiu e ampliou o sistema. Para recompensar a retomada de parte dos serviços, o Estado recalculou o valor para a concessão dos serviços, que passaram a propiciar uma renda (em valores arredondados) superior a 28:000\$000 (vinte e oito contos de réis) aos cofres públicos (Espírito Santo, 1925, p. 40-41).

Iniciativas do poder público, transferindo o direito de exploração dos serviços quando ainda o aparelho público não tinha condições estruturais de criá-los ou quando a exploração dos serviços se tornou vantajosa para a iniciativa privada, esboçam a estratégia do poder estatal de desenvolver as condições de infraestrutura urbana com a participação da iniciativa privada. Para aqueles serviços que ressentiam da falta de empresários locais capazes de executá-los buscou-se contratar com empresários de fora, como foi o caso dos serviços de iluminação, água e esgoto. Todavia, para os serviços de menor porte (aqueles que exigiam menor capitalização dos empresários, como o de limpeza pública) buscou-se no próprio empresariado local sua satisfação.

A contratação do serviço de limpeza pública com Antenor Guimarães ${ }^{13}$ não foi mera coincidência. Este, além da possível influência no corpo político do Estado, era um dos maiores empresários locais e provavelmente um dos poucos em Vitória com condições de um investimento de tal proporção.

Destaca-se também que a criação de infraestrutura e serviços urbanos constituía aspecto estratégico para o desenvolvimento da cidade, e que a concessão ou a prestação

12 Para o serviço de iluminação pública, foram utilizados três transformadores de 30 kilowatts, localizados na praça Santos Dumont (praça Oito de Setembro), atrás do Palácio Anchieta, e lateral à catedral. A cidade era iluminada com 33 lâmpadas de 50 velas e uma lâmpada Nerust de 50 velas, instalada no largo da igreja (Espírito Santo, 1910, p. 37-39).

13 Antenor Guimarães foi um dos mais importantes empresários de Vitória, atuando no ramo de transporte marítimo de cargas. Foi o primeiro concessionário das docas do porto de Vitória, prestando serviços de estiva e cabotagem. O empresário atuou na indústria de serragem de madeira, transporte terrestre por caminhões e carroças, no comércio de atacado e de representação de vendas de veículos (General Motors e Ford Motors) e, ainda, no serviço de vendas de passagem e entrega e recebimento de cargas a serviço da Companhia da Estrada de Ferro Vitória a Minas e para a Leopoldina Railway, segundo depoimento de sua bisneta, Mariza Neves Guimarães (Mendonça, 2014); Firmas [...], p. 5-6). 
dos serviços urbanos, para atenção a essa finalidade, proporcionou, mesmo que pequeno, um acréscimo na receita do Estado.

Do exposto, o que se observa é que, à medida que a prestação dos serviços estratégicos para o desenvolvimento da cidade exigia mais investimento para expandir a infraestrutura urbana, eles se incorporavam ao controle direto do governo. Embora, em situações em que a iniciativa privada local não tinha condições técnicas para atuar em determinados tipos de investimento, o Estado contratasse com particulares de fora ou incorporasse a criação do serviço, a investigação demonstrou que a esfera de poder estadual atuou criando novas oportunidades de investimento para capitalistas locais por meio da modernização da cidade.

\section{Construção de edifícios públicos}

O interesse nesse momento é analisar o desenvolvimento da atividade de construção em Vitória. Essa atividade surge como realização do processo de diversificação dos investimentos no processo de modernização da cidade a partir da construção de edifícios públicos.

$\mathrm{Na}$ economia estadual, os limites à construção ainda a tornavam fortemente dependente das ações do governo. Como ainda não havia experiência de grande porte nesse ramo no estado, as principais obras de infraestrutura (construção do porto e da Cinco Pontes) foram entregues, primeiramente, à iniciativa estrangeira, como era prática nesse período. Contudo, a modernização da cidade, pelas obras de menor porte ou de edifícios públicos principalmente, permitiu a capitalização dos construtores locais. No processo, muitos desses construtores aperfeiçoaram sua capacidade técnica, auxiliando a execução dos projetos de grande porte acertados pelo Estado com empresas de fora (Campos Júnior, 2005).

Acrescenta-se a isso que a investigação privilegiou a participação dos construtores ou empreiteiros locais, pois eram eles que faziam parte da estrutura econômica e política estadual. Nesse sentido, buscamos expor as articulações da estrutura política com o surgimento dessa iniciativa.

Durante o governo Jerônimo Monteiro, o Cel. Antônio José Duarte ${ }^{14}$ foi o responsável por quase todos os contratos de obras do governo. Além daquelas de construção de edifícios, executou a conclusão do aterro da Vila Moscoso, antigo mangal

14 O Cel. Antônio José Duarte era sócio da importante firma comercial Duarte e Beiriz, localizada em Iconha, e buscou no desenvolvimento da cidade de Vitória oportunidades para novos investimentos como forma de diversificar o capital acumulado a partir do comércio de café. Além da construção do Palácio Domingos Martins e do aterramento do arrabalde do Campinho (Vila Moscoso), foi contratado pelo Estado para construir habitações para funcionários públicos no mesmo bairro e como concessionário do serviço de bondes da cidade (Ferro Carril Suá) (Mendonça, 2014). 
do Campinho, que deu origem a esse novo bairro, contratada pelo valor de 126:000\$000 (cento e vinte e seis contos de réis). Associado a esse serviço, Antônio Duarte também executou a construção da Necrópole, exigida para a remoção dos cemitérios para o arrabalde de Santo Antônio (Espírito Santo, 1910, p. 43-44).

A construção do palácio Domingos Martins, edifício do Congresso estadual, foi também contratada com a empresa do Cel. Antônio Duarte, pela importância de 145:000\$000 (cento e quarenta e cinco contos de réis). A execução das obras, iniciadas em 24 de maio de 1911, foi entregue à responsabilidade do construtor André Carloni. Com as mudanças no projeto, ao valor inicial foi acrescida a importância de 50:000\$000 (cinquenta contos de réis) (Espírito Santo, 1911b, p. 35).

A construção de edifícios públicos ${ }^{15}$ e, de maneira geral, de todas as obras públicas significou uma alternativa de investimento para capitalistas locais, no qual temos as origens do ramo da construção na cidade. Para o desenvolvimento desse ramo foi essencial a participação do Estado, que, para regular e para promover a urbanização da cidade, celebrou diversos contratos com capitalistas locais.

No caso em destaque - atuação do Cel. Antônio Duarte - sua participação em diversos contratos com o governo indica não apenas a importância da esfera comercial na política estadual, principalmente em se tratando dos projetos urbanos, mas também a significância das alianças políticas constituídas subjacente ao aparelho de poder. Dessa maneira, a participação do empresário em conjugação com a do agente político na reconstrução da cidade revela não apenas as estratégias utilizadas pelo capital para se valorizar na produção da cidade, mas também o funcionamento das engrenagens políticas para o processo de acumulação.

\section{Investimento em lotes urbanos}

A transformação do significado econômico da terra, forjada no ritmo da desagregação do sistema escravista, possibilitou ao investimento imobiliário funcionar como mecanismo de preservação do patrimônio. Assim, "[...] a propriedade da terra se transformou, assumindo como outras formas de riqueza o significado de reserva de valor. Paulatinamente, a propriedade da terra passou a ser considerada um patrimônio, independentemente de qualquer exploração produtiva" (Pereira, 2004, p. 34).

$\mathrm{Na}$ economia estadual, a quase inexistência de inversões do excedente acumulado

15 Sobre outros edifícios públicos construídos ou reformados, a exemplo do Palácio Anchieta e, ainda, de edifícios particulares, como Teatro Carlos Gomes e Hotel Império (Mendonça, 2014). 
no comércio de café para atividades produtivas multiplicadoras ${ }^{16}$ se refletiu na imobilização de capital em terra urbana. Ou seja, além das alternativas de investimentos em infraestrutura e serviços urbanos, a propriedade da terra urbana foi reforçada como uma das poucas alternativas de emprego de capital no desenvolvimento da cidade.

Esse tipo de investimento se explica pela perspectiva de o crescimento da cidade produzir a valorização mercantil da propriedade imobiliária. A investigação das estratégias de investimento em terra urbana buscou mostrar o surgimento dessa iniciativa no processo de construção da cidade de Vitória. Assim, vejamos o que segue.

Em outubro de 1905, Brian Barry, gerente da firma de exportação de café Hard Hand, adquiriu, por transferência de Abílio Martins, uma área de $10.080 \mathrm{~m}^{2}$, compreendida dentro do Novo Arrabalde. ${ }^{17}$ A compra de outros lotes localizados na área do Novo Arrabalde se seguiu. No mesmo ano, B. Barry adquiriu, no arrabalde do Suá (área sul do Novo Arrabalde), uma área de $2.421 \mathrm{~m}^{2}$. A aquisição desse terreno de A. S. Youle, que anteriormente havia adquirido a área do Estado, deu-se de forma gratuita. ${ }^{18}$

No ano seguinte, temos uma nova transferência registrada gratuitamente em favor de B. Barry. A nova área adquirida, localizada no arrabalde do Suá, era de $1.095 \mathrm{~m}^{2}$, estando fronteiriça à rua do Riacho. ${ }^{19}$ As transferências gratuitas, embora possam levantar outras suspeitas, servem também para demonstrar como era ineficiente a tentativa do Estado de evitar a concentração da terra urbana.

No ano de 1908, B. Barry adquiriu uma nova área. Medindo 25.736,3 m², situavase na porção norte do Novo Arrabalde. ${ }^{20}$ Dessa forma, o proprietário concentrou, em um curto período de tempo, uma área de 39.332,3 $\mathrm{m}^{2}$. Essa dimensão, ao representar 1,43\% da área do Novo Arrabalde, levadas em conta as pequenas dimensões da cidade naquele tempo, deixa amostra de como foi significativo o interesse de proprietários em acumular terrenos na nova área de expansão da cidade (Mapa 3). E, sendo improvável a edificação dos lotes naquele tempo, o interesse poderia ser apenas um: a expectativa de valorização imobiliária promovida pela projeção de crescimento da cidade.

16 Uma rara exceção foi a criação da fábrica de tecidos, em 1910, por Lizandro Nicoletti, proprietário de casa importadora em Vitória. Mesmo que não se refira ao comércio de café, ainda assim a iniciativa exemplifica uma tentativa de inversão do excedente acumulado no comércio para outras atividades multiplicadoras (Derenzi, 1974).

17 Segundo o plano do Novo Arrabalde, a área compreendia os lotes de número 1366 a 1374, localizados na rua Guarapari, tendo ao fundo o morro do Barro Vermelho (Espírito Santo, 1905a).

18 A dita área compreendia os lotes de número 327 a 330, nos quarteirões 15 e 22 do Novo Arrabalde (Espírito Santo, 1905b).

19 Segundo traçado do plano, a área compreendia os lotes 126 e 127, do quarteirão 14, do atual bairro da Enseada do Suá (Espírito Santo, 1906b).

20 A área envolvia os lotes de número 1480 a 1511, distribuídos nos quarteirões 116, 117 e 1118, tendo como limites a rua Espírito Santo do Rio Pardo, o morro Grande da fazenda Maruípe (pertencente ao próprio B. Barry) e a rua Itabapoana (Espírito Santo, 1908). 


\section{Mapa 3}

Terrenos adquiridos no Novo Arrabalde, em Vitória-ES: maiores aquisições - 1896-1932

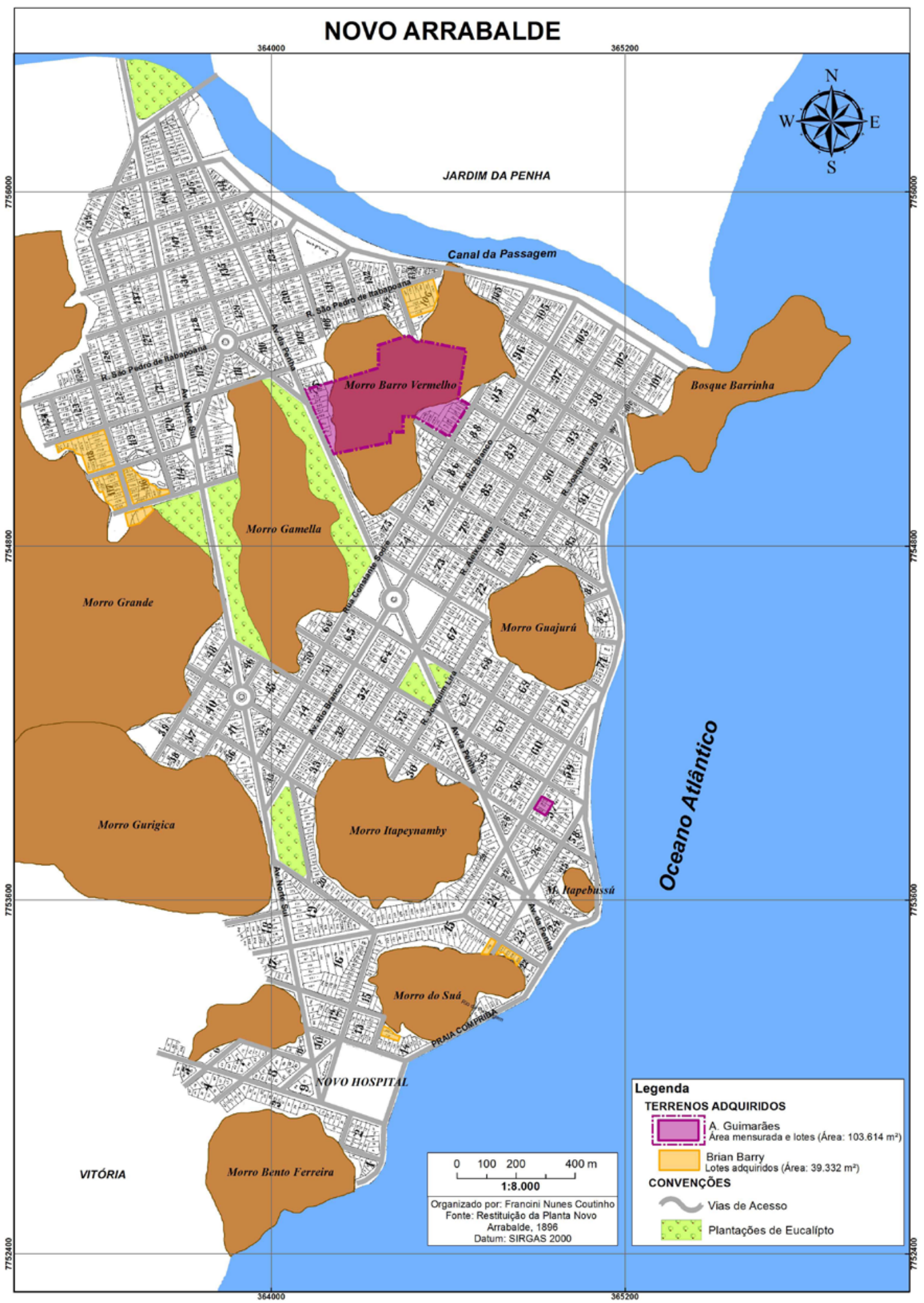

fonte: Produzido a partir de informações dos Processos de Terra do Fundo da Agricultura do Arquivo Público do Estado do Espírito Santo (Mendonça, 2014). 
Outros empresários também agiram nesse desígnio, adquirindo lotes na expectativa de que sua valorização mercantil propiciasse rendas futuras crescentes. ${ }^{21}$ Foi o caso de Antenor Guimarães, que, além de terrenos adquiridos no arrabalde do Campinho ${ }^{22}$ (Vila Moscoso, centro de Vitória), seguiu adquirindo terrenos na região de praias da cidade, que constituíam o Novo Arrabalde.

No arrabalde do Suá, no ano de 1911, A. Guimarães adquiriu lotes de área de 2.016 $\mathrm{m}^{2}$, posteriormente alienados pelo proprietário. ${ }^{23}$ No arrabalde do Barro Vermelho (área compreendida no Novo Arrabalde), A. Guimarães adquiriu, em 1928, uma área de $38.820 \mathrm{~m}^{2}$, e em 1931, outra com $14.882 \mathrm{~m}^{2}$. No Barro Vermelho, somava-se ainda às posses do proprietário uma área de $47.896 \mathrm{~m}^{2}$, totalizando $101.598 \mathrm{~m}^{2}$ (Mapa 3). Sendo assim, os terrenos possuídos no arrabalde do Barro Vermelho compreendiam 3,71\% da área total do Novo Arrabalde $\left(2.738 .098 \mathrm{~m}^{2}\right){ }^{24}$

Assim sendo, o que se verifica a partir do conjunto de estratégias de aquisição de lotes urbanos?

Dadas as condições de urbanização, que se fizeram presentes como desenvolvimento comercial da cidade, os investimentos imobiliários investigados, a princípio, sugerem a perspectiva de a terra urbana servir como reserva de valor, na expectativa de que, com o crescimento da cidade, os proprietários obteriam rendas imobiliárias crescentes.

Com o crescimento econômico da cidade, pela centralidade exercida pelo comércio do café, que promovia a urbanização sob a égide do poder estatal, começava a tornar-se atrativa a transferência do excedente acumulado para a propriedade da terra urbana. A construção da cidade, por consequência, passava a assumir um caráter rentista como estratégia de diversificação do capital e como oportunidade de preservar e valorizar a riqueza para além dos limites da produção agrícola e do comércio.

21 Outro aspecto desse processo foi a propriedade de moradias para aluguel. Informações indicam que o aluguel de moradias já existia em Vitória nos séculos XVIII e XIX (Merlo, 2008; Carvalho, 2010). Contudo, a que tudo indica, essa alternativa de emprego do capital foi intensificada com o crescimento da cidade. Esse foi o caso de Antenor Guimarães, que no arrabalde da Ilha de Santa Maria, nos terrenos conquistados ao mar, durante os anos 1920, tanto ofertava lotes como alugava moradias para operários vindos do interior do estado, atraídos pela oferta de empregos da firma Antenor Guimarães e Companhia (Mendonça, 2014).

22 Em 1904, A. Guimarães adquiriu do Estado uma área de $1.240 \mathrm{~m}^{2}$, com o interesse em construir habitações para funcionários, e, em 1906, adquiriu na mesma região uma área de $1.750 \mathrm{~m}^{2}$, fronteiriça ao quartel de polícia, ambos os terrenos no arrabalde do Campinho (Vila Moscoso). No mesmo bairro, A. Guimarães já havia aforado um lote fronteiriço à rua Vinte e Três de Maio, onde construiu sua residência particular (Espírito Santo, 1906a, 1914).

23 Essa área compreendia os lotes 677, 678 e 679 do Novo Arrabalde. Porém, em março de 1914, foi transferida por 500\$000 (Espírito Santo, 1911a).

24 A identificação da localização dos terrenos refere-se ao morro do Cemitério, mais conhecido como morro do Barro Vermelho, nas adjacências do encontro entre a avenida Nossa Senhora da Penha e a rua Constante Sodré (ou São Mateus), incluindo a rua Itapemirim, onde foi formada a Chácara Paraíso e hoje está localizado o Edivit. Importante observar que essas aquisições não seguiram o traçado original do plano (Espírito Santo, $1928,1931)$ 


\section{Considerações finais}

Diante das limitadas condições do excedente acumulado na esfera do comércio, em se desdobrar em atividades produtivas multiplicadoras de riqueza, como a indústria, o investimento em terra urbana surgiu, desde os primórdios da modernização da cidade, como uma alternativa para preservar o poder econômico, que se transformava no processo de metamorfose das formas de riqueza.

Portanto, no conjunto das transformações socioeconômicas indicadas, revelaramse novas alternativas de valorização do capital na construção da cidade por meio da criação de infraestrutura e prestação de serviços urbanos, mas também se originaram as primeiras estratégias de investimento patrimonial a partir da projeção da valorização da propriedade imobiliária.

Contudo, na estrutura produtiva regional, a concentração de riqueza na esfera do comércio estabeleceu um ritmo mais lento à valorização da terra, impedindo o rápido e alto retorno do valor investido na compra de terra. Todas as estratégias de investimento em lotes urbanos esboçam a ação de proprietários na perspectiva de usufruir futuramente de valorização imobiliária. No entanto, essas estratégias só se concretizaram décadas adiante.

Iniciativas como essas refletem a perspectiva por parte dos capitalistas locais de valorização futura da propriedade imobiliária. Pois, como reserva de valor, a propriedade de terra na cidade funcionava como fundo de acumulação e, dada a perspectiva de continuidade de crescimento da cidade, aparecia não só como meio de preservação do patrimônio, mas como um investimento capaz de aumentar a riqueza do proprietário.

Para a constituição da centralidade urbana fundada no comércio, foi necessário criar condições materiais (espaço): a cidade precisou ser produzida com essa nova feição, isto é, precisou materializar as condições para a atividade comercial (infraestrutura de transporte e armazenamento de mercadorias: estradas, pontes, armazéns e porto).

Nesse processo, a produção da cidade como materialidade espacial criou novas alternativas para valorizar o capital, por meio de obras públicas e da construção privada de equipamentos de serviços urbanos: construção de edifícios (públicos e privados) e habitações, fornecimento de água e energia elétrica, coleta de lixo e transporte urbano e de cargas. Todo esse conjunto de obras e atividades de serviços, criado com a ampliação dos circuitos de valorização do capital, passou a engendrar ações do capital a fim de extrair renda pela perspectiva de valorização da propriedade imobiliária. É o que se constata ao se analisar a estratégia de capitalistas locais na aquisição de lotes urbanos, como no caso de Antenor Guimarães e Brian Barry, que adquiram grandes somas de terra urbana na área do Novo Arrabalde.

\section{Referências}

ABREU, M. A. Sobre a memória das cidades. Revista Território, Rio de Janeiro, v. 3, n. 4, p. 5-26, 1998. 
ARAÚJO FILHO, J. R. O porto de Vitória. São Paulo: Departamento de GeografiaUSP, 1974.

BITTENCOURT, G. A. M. A formação econômica do Espírito Santo: o roteiro da industrialização, do engenho às grandes indústrias (1535-1980). Rio de Janeiro: Cátedra, 1987.

BRITO, F. S. R. Projeto de um novo arrabalde. Vitória: Apees, 1896.

CAMPOS JÚNIOR, C. T. A história da construção e das transformações da cidade. Vitória: Cultural-ES, 2005.

A construção da cidade: formas de produção imobiliária em Vitória. Vitória: Florecultura, 2002.

O novo arrabalde. Vitória: Secretaria Municipal de Cultura e Turismo, 1996.

CARVALHO, E. F. Redes mercantis: a participação do Espírito Santo no complexo econômico colonial (1890 a 1821). Vitória: Secult, 2010.

DERENZI, L. S. Os italianos no estado do Espírito Santo. Rio de Janeiro: Artenova, 1974.

. Biografia de uma ilha. Rio de Janeiro: Pongetti, 1965.

ELTON, E. Logradouros antigos de Vitória. Vitória: IJSN, 1986.

FAORO, R. Os donos do poder: formação do patronato político brasileiro. São Paulo: Globo, 2008.

FIRMAS que honram o Espírito Santo: Antenor Guimarães e Cia. Ltda. A Gazeta, Vitória, 11 set. 1949. p. 5-6.

HARVEY, D. O trabalho, o capital e o conflito de classes em torno do ambiente construído nas sociedades capitalistas avançadas. Espaço e Debate - Revista de Estudos Regionais e Urbanos. São Paulo, v. 2, n. 6, p. 6-35, 1982.

LEFEBVRE, H. A revolução urbana. Belo Horizonte: Editora UFMG, 1999.

MARTINS, J. S. O cativeiro da terra. São Paulo: Hucitec, 1996. 
MARX, K. A fórmula trinitária do valor. In: O capital: crítica da economia política.. São Paulo: Difel, 1985[1894]. p. 935-954. v. 3.

MENDONÇA, M. C. A modernização do atraso: os fundamentos da urbanização de Vitória - 1889-1930. Dissertação (Mestrado em Geografia) - Centro de Ciências Humanas e Naturais, Universidade Federal do Espírito Santo, Vitória, 2014.

MERLO, P. M. S. O nó e o ninho: estudo sobre a família escrava em Vitória, Espírito Santo, 1800-1871. Tese (Doutorado em História) - Instituto de Filosofia e Ciências Sociais, Universidade Federal do Rio de Janeiro, Rio de Janeiro, 2008.

OLIVEIRA, F. O Estado e o urbano no Brasil. Espaço e Debate - Revista de Estudos Regionais e Urbanos, São Paulo, v. 2, n. 6, p. 36-54, 1982.

PEREIRA, P. C. X. São Paulo: a construção da cidade (1872-1914). São Paulo: Rima/ Fapesp, 2004.

Espaço, técnica e construção: o desenvolvimento das técnicas construtivas e a urbanização do morar em São Paulo. São Paulo: Nobel, 1988.

QUINTÃO, L. C. A interiorização da capital pela Estrada de Ferro Sul do Espírito Santo. Dissertação (Mestrado em História) - Centro de Ciências Humanas e Naturais, Universidade Federal do Espírito Santo, Vitória, 2008.

SALETTO, N. Transição para o trabalho livre no Espírito Santo (1888-1930). Vitória: Edufes, 1996.

SIQUEIRA, P. O desenvolvimento do porto de Vitória, 1870-1940. Vitória: Codesa/ FCAA, 1984.

WERNICKE, H. Viagem pelas colônias alemãs do Espírito Santo: uma viagem até os cafeicultores alemães em um estado tropical do Brasil. Vitória: Apees, 2013[1910].

\section{Fontes primárias}

ESPÍRITO SANTO (Estado). Arquivo Público do Estado do Espírito Santo. Processos de terra [Antenor Guimarães], n. 8413. Fundo da Agricultura, II Série (impresso, caixa 380), 1931.

ESPÍRITO SANTO (Estado). Arquivo Público do Estado do Espírito Santo. Processos 
de terra [Antenor Guimarães], n. 8402. Fundo da Agricultura, II Série (impresso, caixa 380), 1928.

ESPÍRITO SANTO (Estado). Arquivo Público do Estado do Espírito Santo. Presidente Florentino Avidos. Mensagem apresentada ao Congresso Legislativo pelo presidente Florentino Avidos (1924-1928). Vitória, [s.i.], 1925.

ESPÍRITO SANTO (Estado). Arquivo Público do Estado do Espírito Santo. Processos de terra [Antenor Guimarães], n. 3978. Fundo da Agricultura, Il Série (microfilme), 1914.

ESPÍRITO SANTO (Estado). Arquivo Público do Estado do Espírito Santo. Processos de terra [Antenor Guimarães], n. 4061. Fundo da Agricultura, II Série (microfilme), 1911a.

ESPÍRITO SANTO (Estado). Arquivo Público do Estado do Espírito Santo. Diretor de Agricultura, Terras e Obras [Dr. Antônio Francisco de Athayde]. Relatório do governo Jerônimo Monteiro (1908-1912). Vitória: Imprensa Estadual, jul. 191 lb.

ESPÍRITO SANTO (Estado). Arquivo Público do Estado do Espírito Santo. Diretor de Agricultura, Terras e Obras [Dr. Antônio Francisco de Athayde]. Relatório do governo Jerônimo Monteiro (1908-1912). Vitória: Imprensa Estadual, jul. 1910.

ESPÍRITO SANTO (Estado). Arquivo Público do Estado do Espírito Santo. Diretor de Viação e Obras Públicas [Dr. Ceciliano Abel de Almeida]. Relatório do governo Jerônimo Monteiro (1908-1912). Vitória: Imprensa Estadual, jul. 1909.

ESPÍRITO SANTO (Estado). Arquivo Público do Estado do Espírito Santo. Processos de terra [Brian Barry], n. 3973. Fundo da Agricultura, II Série (microfilme), 1908.

ESPÍRITO SANTO (Estado). Arquivo Público do Estado do Espírito Santo. Processos de terra [Antenor Guimarães], n. 3977. Fundo da Agricultura, II Série (microfilme), 1906 a.

ESPÍRITO SANTO (Estado). Arquivo Público do Estado do Espírito Santo. Processos de terra [Brian Barry], n. 3972. Fundo da Agricultura, Il Série (microfilme), 1906b.

ESPÍRITO SANTO (Estado). Arquivo Público do Estado do Espírito Santo. Processos de terra [Brian Barry], n. 3993. Fundo da Agricultura, II Série (microfilme), 1905a.

ESPÍRITO SANTO (Estado). Arquivo Público do Estado do Espírito Santo. Processos 
de terra [Brian Barry], n. 3974. Fundo da Agricultura, II Série (microfilme), $1905 \mathrm{~b}$.

ESPÍRITO SANTO (Estado). Arquivo Público do Estado do Espírito Santo. Processos de terra [Antenor Guimarães], n. 3979. Fundo da Agricultura, II Série (impresso, caixa 256), 1904.

\section{Entrevistas}

MENDONÇA, M. C. Entrevista com Mariza Neves Guimarães. Vitória-ES, 31 jan. 2014. 